\title{
Analysis used for the installation of an IFMSW processing center for cement plants in the state of Hidalgo, Mexico
}

\author{
J. E. Sánchez, J. A. Araiza \& M. N. Rojas-Valencia \\ Engineering Institute, UNAM, Mexico
}

\begin{abstract}
In the last few years, municipal solid waste has become a very important issue in many countries, especially Mexico. Waste has evolved during the last decades as regards both volume and composition, mainly because of population growth, changes in consumption habits and an inefficient management by the local environmental authorities and society itself, leading to negative impacts on several environment areas such as underground and surface waters, air and soil. In order to prevent environmental contamination, it is necessary to install a waste management infrastructure that fulfills standard requirements. This document discloses the analysis conducted to select sites that fulfill standard technical and environmental requirements based on a multi-criteria evaluation of the geographic information systems for installing a processing center for the inorganic fraction of municipal solid waste in the state of Hidalgo. Currently, there are few centers of this type in Mexico and most of them do not comply with these requirements leading thus to inefficiencies.

Keywords: waste management infrastructure, multi-criteria evaluation, geographic information systems, inorganic fraction of waste, state of Hidalgo.
\end{abstract}

\section{Introduction}

In Mexico, over 102, 000 tons of Municipal Solid Waste (MSW) are generated daily, $2 \%$ of it being generated in the state of Hidalgo (equivalent to $1,870 \mathrm{t} /$ day), mainly from housing, parks, gardens and public buildings INECC [1]. The MSW management infrastructure in the state is traditional and waste is disposed of in open dumping sites. Most of the times, the recovery of useful materials is made by very low income people working in unhygienic conditions. Moreover, waste is 
very often incinerated because of the lack of municipal sanitation services. This situation places the state of Hidalgo in an unfavorable position in the handling and use of MSW compared to the other states of the Mexican Republic (Sánchez [2]).

The main obstacle for an appropriate management of MSW relates to the infrastructure required for handling waste that, depending on their physical and chemical characteristics, may potentially be recovered. There is thus a need to build an appropriate infrastructure for the various activities of the waste management chain including collection centers, selection plants, processing centers and final disposal sites.

In parallel with management and harnessing of waste, concrete is the second most consumed material in the world after water and its main component is cement. The cement manufacturing process requires intensive use of fuels. In Mexico, since 2011, the cement company CEMEX has been conducting research on an alternative source of fuel, in order to save energy and lower gas emissions to the atmosphere. This alternative source of fuel is the Inorganic Fraction of Municipal Solid Waste (IFMSW). In order to tap this energy, it is necessary to separate the waste (especially the waste having a high calorific power), or any fuel material derived from MSW, in an IFMSW, submit them to a thermal treatment, especially co-processing, which is of great interest to the cement companies.

In this context, this work analyzes the installation of an IFMSW processing center in the state of Hidalgo to mitigate the negative environmental impacts caused by the disposal of waste in landfills or open dumping sites and to permit the recycling and use of the inorganic fraction as a source of alternative fuel through co-processing.

\section{Waste regulations and management in the state of Hidalgo}

\subsection{Regulations}

Mexican environmental regulations govern the location, building, operation and closure of MSW final disposal sites as well as the sites where Waste requiring Special Handling (WSH) and dangerous waste is confined. At state level, only the state of Mexico has a standard containing the requirements and specifications for the installation, operation and maintenance of the infrastructure for the collection, transfer, selection and use of MSW. In the specific case of the state of Hidalgo, there is no robust legislation regulating the installation and operation of MSW processing centers or selection plants.

This work includes standardized environmental criteria, a compilation and analysis of most of the current restrictions in the Mexican regulations (laws, standards, rules and criteria) as regards the building of infrastructure related to the selection and processing (energetic valorization) of MSW; as well as technical criteria, restrictions as regards topography (land slopes), access and transportation roads and origin of the waste.

The following Mexican standards were considered to establish the location of the IFMSW processing center: Mexican official norm for the building and operation of final disposal sites (NOM-083 [3]); the manual related to the 
installation of transfer stations (Sánchez et al. [4]); the manual of technical criteria for the location, operation and closure of environmental infrastructure for collecting, transferring, separating and treating Municipal Solid Waste and Waste requiring Special Handling (SEMARNAT [5]); the technical standard related to the requirements and specifications for installing and operating collection, transfer, separation and treatment centers for MSW and WSH in the state of Mexico (NTEA-010 [6]); and the environmental standard establishing the criteria and technical specifications under which the separation, classification, selective collection and storage of waste in Mexico City must be conducted in order to promote its use and prevent its generation (NADF-024 [7]).

\subsection{Current situation in the management of the RSU}

Solid waste management in the state of Hidalgo faces many difficulties, such as inappropriate separation, limited environmental culture, social resistance to the building of infrastructure for handling and using MSW and lack of economic resources for installing said infrastructure. The state is formed by 84 municipalities with 4,596 settlements and a population of 2,826, 650 inhabitants. Figure 1 shows the projection of MSW generation for the year 2,045, based on data from the year 2015 (estimates calculated by the arithmetic method) in the municipalities of Hidalgo having over 45, 000 inhabitants (INEGI BII [8]). Mineral de Reforma and Pachuca are the municipalities that will be generating most waste in 2,045.

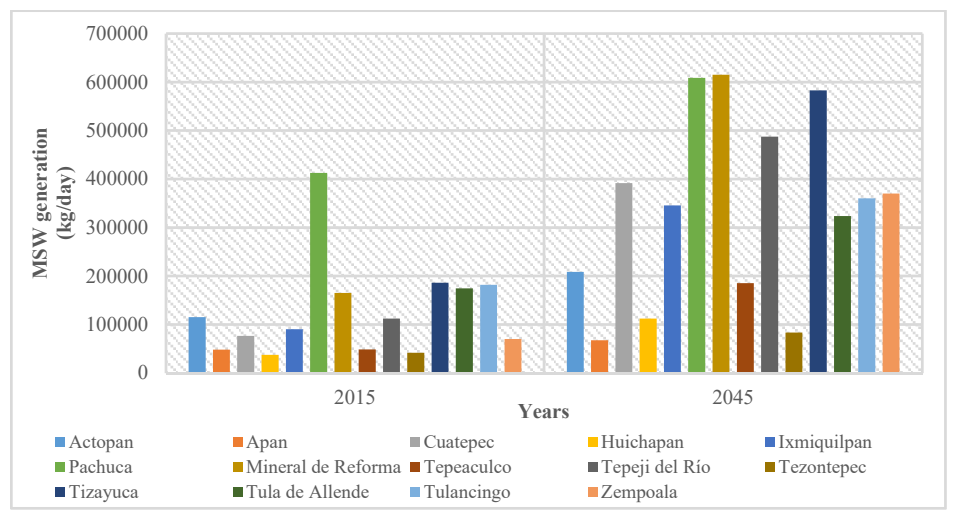

Figure 1: Projection of waste generation in the municipalities of Hidalgo.

The average percentage composition of the waste generated in Hidalgo is as follows: organic waste (food and garden waste): 34\%; recoverable waste (cardboard, tetra-pak, metals, paper, plastic, glass, PET, PEAD, amongst others): $30 \%$; non-recoverable waste (basically various materials such as plastics, rubber, sanitary paper, diapers, cardboard and textiles): 36\% (PEPGIR [9]). 


\subsubsection{Infrastructure of management and harnessing of MSW}

Most of the waste handling sites and cement plants are located in the southeast of the state of Hidalgo. This was the first criterion taken into account to delimitate the study area to propose the optimal location of an IFMSW processing center.

\section{Energetic valorization of the solid waste as alternative fuels}

Mostly, alternative fuels are agricultural waste or by-products of industrial, domestic, agricultural and forestry processes, including used tires and oils, IFMSW, processed biomass such as rice and coffee husks, sewage sludge, amongst others. Alternative fuels generate several benefits for the environment, such as the reduction of the use of non-renewable conventional fossil fuels, the provision of an ordered, final and ecologically responsible solution to waste disposal that leads to the prevention of landfills saturation, the reduction of the emission of greenhouse gases to the atmosphere and, above all, its use as energy source.

IFMSW is obtained selecting waste that cannot be recycled because they are contaminated or too small. Said waste include glass, PET, aluminum, paper, cardboard, etc. as well as hospital waste and waste requiring special handling that cannot be further treated such as diapers, batteries, syringes, metals, among others. This selection process leads to the obtainment of two mixtures of organic waste: one having a faster degradation speed and another having a slower degradation speed, known as IFMSW. It is separated, compacted and wrapped to be then used as alternative fuel in cement kilns. Because the amount of the ash generated by the combustion of the IFMSW is minimal, it is possible to incorporate it into cement manufacturing process. It is noteworthy to mention that the composition of the oxides of the ash that is compatible with the composition of the clinker, which closes the co-processing cycle and does not affect the quality of the properties of the raw material of the cement.

\subsection{Co-processing in cement kilns}

Cement manufacturing is an energy-intensive process because of the high temperatures it requires.

The energy consumption depends in part on the raw materials used, but mainly on the technology and the feeding system employed, wet feeding systems requiring the evaporation of the water introduced with the raw materials. Under these circumstances, fuel consumption in the clinker rotary kiln ranges from 700 to $1,300 \mathrm{kcal} / \mathrm{kg}$ of clinker (from 3,000 to $5,500 \mathrm{MJ} / \mathrm{t}$ ), which is equivalent to 100 to $185 \mathrm{~kg}$ of coke per ton of cement. Traditionally, this energy has been supplied by various fossil fuels such as oil, coke, coal, fuel oil and natural gas (Cedano [10]).

The difference between co-processing and conventional incineration is that, in the case of co-processing, both the energy and the minerals present in the waste is used. This is because the high temperatures (approximately $2,000^{\circ} \mathrm{C}$ ) and a residence time greater than 5 seconds generate a self-cleaning process of the gases 
in an alkaline atmosphere, so that the ashes can be integrated to the cement manufacturing process. On the other hand, waste incineration produces ashes that have to be further treated, and generates polluting gases that are emitted to the atmosphere because of an inappropriate process control (Rojas-Valencia and Marín [11]).

Before using alternative fuels, it is necessary to process them in order to limit their contents of given elements such as organic matters, chlorine, heavy metals, among others. This is done to ensure that they will not negatively impact the process itself, or the quality of the final product, or the environment. Moreover, an energetic valorization as well as a strict quality validation must be performed.

\subsection{MSW calorific value}

Waste is an important source of energy the calorific value of which can be used through thermal processes such as incineration and co-processing or through the use of biogas from landfills and anaerobic digesters.

An important factor for the generation of energy from MSW treatment is the energetic content or calorific value that indicates the quantity of heat that a body may emit to determine whether the waste is suitable for producing energy or will only consume a greater amount of energy and make the process less profitable.

Because of this, thermal treatments must always be accompanied by MSW pretreatment or processing in order to obtain the waste fraction of interest. The objective of this material conditioning is to use the higher percentage of waste that comply with the treatment requirements. The calorific value may vary depending on the waste. However, it is not only the calorific value which is relevant but also the mineral content (ash) of the waste. Through combustion, a MSW volume reduction comprised between 85 and $90 \%$ is obtained (Choy et al. [12]). Most MSW can be used as a fuel option in kilns because although their minimum calorific value is $10.70 \mathrm{MJ} / \mathrm{kg}$, which is lower than commonly used fuels, their calorific value vs volume ratio must be taken into account. Table 1 shows a comparison of the most representative calorific values, of both commonly used fossil fuels and waste according to Rojas-Valencia and Marín [11].

Table 1: Calorific values of MSW vs. fossil fuels.

\begin{tabular}{|c|c|c|c|}
\hline $\begin{array}{c}\text { Commonly used } \\
\text { fossil fuel }\end{array}$ & Calorific value (MJ/kg) & Collected waste & $\begin{array}{c}\text { Calorific value } \\
\text { (MJ//kg) }\end{array}$ \\
\hline Coke & 33.49 & Mixed plastics & 32.70 \\
\hline Natural gas & 48 & Cardboard & 26.20 \\
\hline Fuel oil & 44 & Textiles & 18.30 \\
\hline Coal & 29 & Mixed paper & 15.70 \\
\hline Lignite & 20 & MSW & 10.70 \\
\hline \multicolumn{2}{|r}{} & Mixed food & 4.20 \\
\hline
\end{tabular}

The calorific value of the combined MSW is 6 to $14 \mathrm{MJ} / \mathrm{kg}$. The total energy content of waste is exploited more efficiently through thermal processes. During combustion, energy is obtained directly from biomass sources (waste paper, wood, 
natural textile material and food) and fossil coal (tires, plastics and synthetic textile materials) (Queiroz et al. [13]).

The quantification of the calorific value has been performed on several samples from IFMSW bales arriving at CEMEX plant in Huichapan, Hidalgo. The quarter method was used to obtain $1.0 \mathrm{~g}$ of IFMSW compound sample and analyze its calorific value.

Five samples were taken from various bales in July and September. The results obtained are shown in Table 2. Variable calorific values are obtained because of the different types of waste that the selected sample may contain and the various climatological conditions. The average value was $18.26 \mathrm{MJ} / \mathrm{kg}$.

Table 2: $\quad$ Results of the analysis of the calorific value performed on samples from IFMSW bales.

\begin{tabular}{|c|c|c|}
\hline Date of obtainment of the sample & Calorific value (cal/g) & Calorific value (MJ/kg) \\
\hline 03-July-15 & 4,300 & 18.00 \\
\hline 06-July-15 & 4,104 & 17.18 \\
\hline 10-July-15 & 4,316 & 18.07 \\
\hline 18-September-15 & 4,850 & 20.31 \\
\hline 21-September-15 & 4,232 & 17.72 \\
\hline \multicolumn{2}{|l}{} \\
\hline
\end{tabular}

\subsection{Processing systems to generate IFMSW bales}

The processing systems have been designed to be located in strategic places taking into account environmental, social and economic aspects. Mobile or fixed plants may be available. Mobile plants are installed for a given period of time at the origin of the materials to be used as alternative fuels, carrying out the sanitation of a specific site, one at a time. The fixed processing systems allow practical improvements in the MSW management leading to a better use of the waste in different areas, such as recycling and alternative fuels in cement kilns.

Figure 2 shows a model of the proposed infrastructure for the IFMSW processing center (fixed) to process the MSW generated in the state of Hidalgo. First, the waste is transported from different disposal sites or towns through garbage trucks. Then, they are deposited in a reception pit and placed in a hopper to be transported and processed through two selection lines to various reduction, separation and compaction equipment. Processing starts with a pre-grinding to break bags, then the waste go through trommeles that separate the fermentable organic materials from non-fermentable materials, known as the inorganic fraction that is in turn submitted to a manual selection to separate the recyclable materials (PET, cardboard, glass, metal, leather, paper, wood, etc.) that are compacted to be transported to recycling companies or collection centers. The ferrous waste that may still be in the selection line are separated from the remaining (rejected) inorganic fraction through magnetic separators. Finally, the rejected IFMSW are compacted and wrapped in stretch plastic film to form bales that optimize their handling and transportation to the cement plants. 


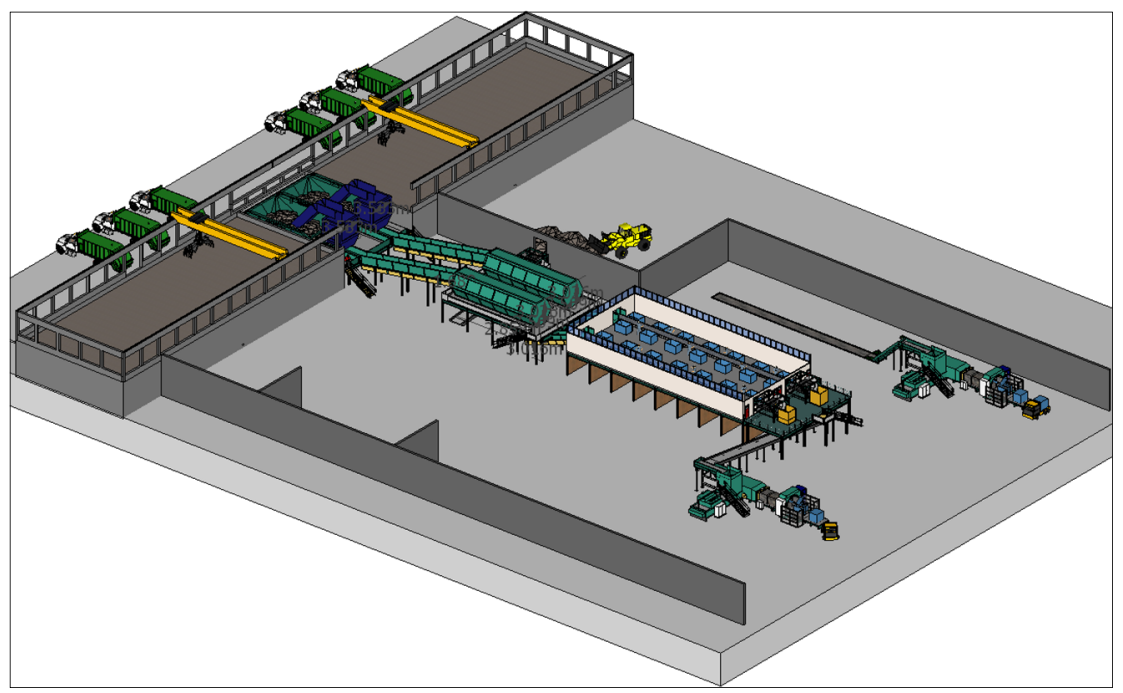

Figure 2: Model of the infrastructure of the IFMSW processing center (fixed).

The capacity of the IFMSW processing center in 20 years based on the projection and composition of the waste generated in Hidalgo is 2,474 t/day and its infrastructure would require a total surface of about two hectares. The plant will process $120 \mathrm{t} / \mathrm{h}$ and operate two selection lines, 20 working hours per day divided in 2 shifts. The estimated total cost of the installation and commissioning of each one of the lines is $\$ 62,388,558.00 \mathrm{MXN}$. The cost estimate was jointly established with the company MASIAS RECYLING from Spain.

\section{Evaluation and selection of the optimal site for installation of the IFMSW processing center}

In various zones of Mexico, infrastructure for the MSW management is available. However, in most of the cases, the plants operate in inappropriate conditions, generating health risks and damages to the environment. This is due to the lack of an appropriate legal and technical framework in the states of the republic and in other cases their functioning is inefficient because a determination of the optimal location in environmental, technical and economic terms was not performed.

Geographic Information Systems (GIS) are important supporting tools to generate maps, environmental and land use planning. These tools are important because besides permitting to manipulate environmental and technical variables, they incorporate GIS-based procedures with georeferenced information, and the decision making is reinforced by the opinion and validation of experts in the development and application of the information through various techniques (Olivas et al. [14]).

In Mexico, as well as in other parts of the World, there exist previous experiences in which procedures have been used with GIS tools to locate the places 
considered for building transfer stations (Araiza [15]) and centers for waste recovery (Roé et al. [16]). However, they have not been used for locating the optimal sites for the installation of an IFMSW processing center.

\subsection{Multi-criteria evaluation to determine the most suitable areas for the location of the IFMSW processing center}

For the evaluation of the location criteria, various methods are available, not only to identify potential areas for MSW management but also for the location of other type of infrastructures such as hydroelectric stations, ports, highways, among others. One of the most commonly applied methods is the Multi-Criteria Evaluation (MCE) that uses GIS for its implementation (Herrera [17]). MCE refers to a group of decision-making operations, taking into account simultaneously several criteria or conditioners. The proposed method facilitates suitability grading and differential weighting of the criteria in the final decision. MCE in a GIS environment implies the use of geographic data and the manipulation of the information according to defined decision rules. Moreover, indicators linked to environmental and technical criteria must be taken into account (De Pietri et al. [18]).

The study area is the south of the state of Hidalgo (see Figure 4). The main waste handling sites and cement plants were previously located and georeferenced. It was found that all of them were in the southern part of the state and the study area was defined based on this information.

\subsubsection{Approach and development of the MCE in the GIS environment}

The approach consisted in the application of one of the most studied MCE techniques, denominated "Hierarchical Analysis Process" (HAP) to determine a group of suitable preliminary areas where the IFMSW Processing Center could be located. This technique was chosen mainly because it permits to identify the parts forming the system as well as their links, acknowledging the weight of each one of the parts and proposing a rational solution.

Satty, the creator of the technique, indicates that HAP consists of dividing a complex problem or situation into its parts or variables, performing a hierarchical order arrangement to assign numerical values to each part according to subjective judgments based on the relative importance of each part or variable, so as to synthesize them to determine the ones of greater priority (Satty [19]).

The hierarchical scheme usually consists of three basic levels: main objective, decision criteria (usually accompanied with specific criteria), and solution alternatives. Its mathematical formula is given in equation (1).

$$
\boldsymbol{R}_{i}=\sum_{k} w_{k} \boldsymbol{r}_{i k}
$$

wherein " $\mathrm{W}_{\mathrm{k}}$ " is the priority (weight) vector associated to each element " $\mathrm{k}$ " of the criteria hierarchical structure. The sum " $\mathrm{W}_{\mathrm{k}}$ " is equal to 1 and " $\mathrm{r}_{\mathrm{ik}}$ " is the priority vector obtained upon comparing the alternatives with each criteria.

Before applying an MCE technique to a SIG environment, it is important to establish the criteria that will impact the reception capacity of the territory (Gómez 
and Barredo [20]). The location criteria (general criteria) used in this work were divided into three parts: environmental, socioeconomic and technical criteria. In turn, the so called general criteria were divided into specific criteria and organized according to two aspects: "factor and constraints", the "factors" being the variables that must have more than two categories or levels, while the "constraints" may have a maximum of only two levels.

\subsubsection{Criteria weighting and standardization}

To perform the general and specific criteria weighting (Wgc and Wsc), the pair comparison developed by Saaty [19] was modified. The relative importance scale with values ranging from 1 to 9 was not directly used, but was substituted by the percentage scale. Table 3 shows the example of the environmental criteria, in which is shown how these values are.

For the standardization of the levels (SL) of the specific criteria, a simple weighting of values from 1 to 3 was applied to the factors and from 0 and 1 to the restraints; wherein the smallest value indicates the least favorable condition, while the highest value indicates the most favorable condition.

Table 3: Weighting and standardization of environmental criteria.

\begin{tabular}{|c|c|c|c|c|c|}
\hline Wgc & $\begin{array}{l}\text { Specific } \\
\text { criteria }\end{array}$ & Wsc & \multicolumn{2}{|l|}{ Description } & SL \\
\hline \multirow{11}{*}{$\begin{array}{l}0 . \\
35\end{array}$} & \multirow{3}{*}{$\begin{array}{c}\text { Water } \\
\text { bodies and } \\
\text { streams }\end{array}$} & \multirow[b]{3}{*}{0.25} & \multirow{3}{*}{$\begin{array}{l}\text { The surface water bodies and streams and, } \\
\text { above all, the ones of continuous flow } \\
\text { must be at least } 500 \mathrm{~m} \text { away from the } \\
\text { location of any MSW handling } \\
\text { infrastructure. }\end{array}$} & $>1000 \mathrm{~m}$ & 3 \\
\hline & & & & $500-1000 \mathrm{~m}$ & 2 \\
\hline & & & & $<500 \mathrm{~m}$ & 1 \\
\hline & \multirow[b]{3}{*}{$\begin{array}{c}\text { Water } \\
\text { extraction } \\
\text { wells }^{1}\end{array}$} & \multirow[b]{3}{*}{0.25} & \multirow{3}{*}{$\begin{array}{l}\text { The exploitation of underground water for } \\
\text { supplying residential areas, industries, } \\
\text { watering systems, drinking water for } \\
\text { cattle, both in operation as well as } \\
\text { abandoned must be at least } 500 \mathrm{~m} \text { away } \\
\text { from the possible location of any MSW } \\
\text { handling infrastructure. }\end{array}$} & $>1000 \mathrm{~m}$ & 3 \\
\hline & & & & $500-1000 \mathrm{~m}$ & 2 \\
\hline & & & & $<500 \mathrm{~m}$ & 1 \\
\hline & \multirow{3}{*}{ Soil types ${ }^{1}$} & \multirow{3}{*}{0.25} & \multirow{3}{*}{$\begin{array}{l}\text { The permeability of a soil determines the } \\
\text { contamination level that can be caused by } \\
\text { a MSW handling infrastructure through } \\
\text { leachates and other liquid waste. Sites } \\
\text { with sedimentary soils having sand-clay } \\
\text { characteristics will be preferred because of } \\
\text { their low permeability. }\end{array}$} & $\begin{array}{c}\text { Slow } \\
\text { permeability }\end{array}$ & 3 \\
\hline & & & & $\begin{array}{c}\text { Moderate } \\
\text { permeability }\end{array}$ & 2 \\
\hline & & & & $\begin{array}{c}\text { Rapid } \\
\text { permeability }\end{array}$ & 1 \\
\hline & \multirow{2}{*}{$\begin{array}{l}\text { PNAs and } \\
\text { others }^{1}\end{array}$} & \multirow[b]{2}{*}{0.25} & \multirow{2}{*}{$\begin{array}{l}\text { The MSW handling infrastructure must } \\
\text { not be located in protected natural areas, } \\
\text { and other areas of relevance. The } \\
\text { cartography published by CONANP [21] } \\
\text { was used to generate this layer. }\end{array}$} & $\begin{array}{c}\text { Outside } \\
\text { zones }\end{array}$ & 1 \\
\hline & & & & Inside zones & 0 \\
\hline
\end{tabular}

${ }^{1}$ Criterion based on NOM-083[3].

Figure 3 shows the maps on which the MCE was developed. The final map was obtained through the sum of the various maps of each one of the criteria (general and specific) showing the study zone classified in four levels, based on the degree of suitability for the installation of the IFMSW processing center. 
Areas classified as low suitability $\left(5,465 \mathrm{~km}^{2}\right)$ predominate, mainly in the southeast and northeast of the territory, while $4,086 \mathrm{~km}^{2}$ correspond to medium suitability areas because they are very close to zones having surface water bodies and crops.

An area of $3,122 \mathrm{~km}^{2}$ of the study zone is highly suitable. It is mainly concentrated in a radio of 20 to $30 \mathrm{~km}$ to the north and northeast of the limit of the capital of the state (Pachuca, Hidalgo). Other small areas having the same level of suitability exist, but further analysis is necessary to determine feasibility.

Special attention must be given to the region which has not been shaded (restricted level) in the northern part of the study area, which was immediately rejected by the MCE technique because it corresponds to natural relevant zones and other smaller zones where considerable urban areas are located.

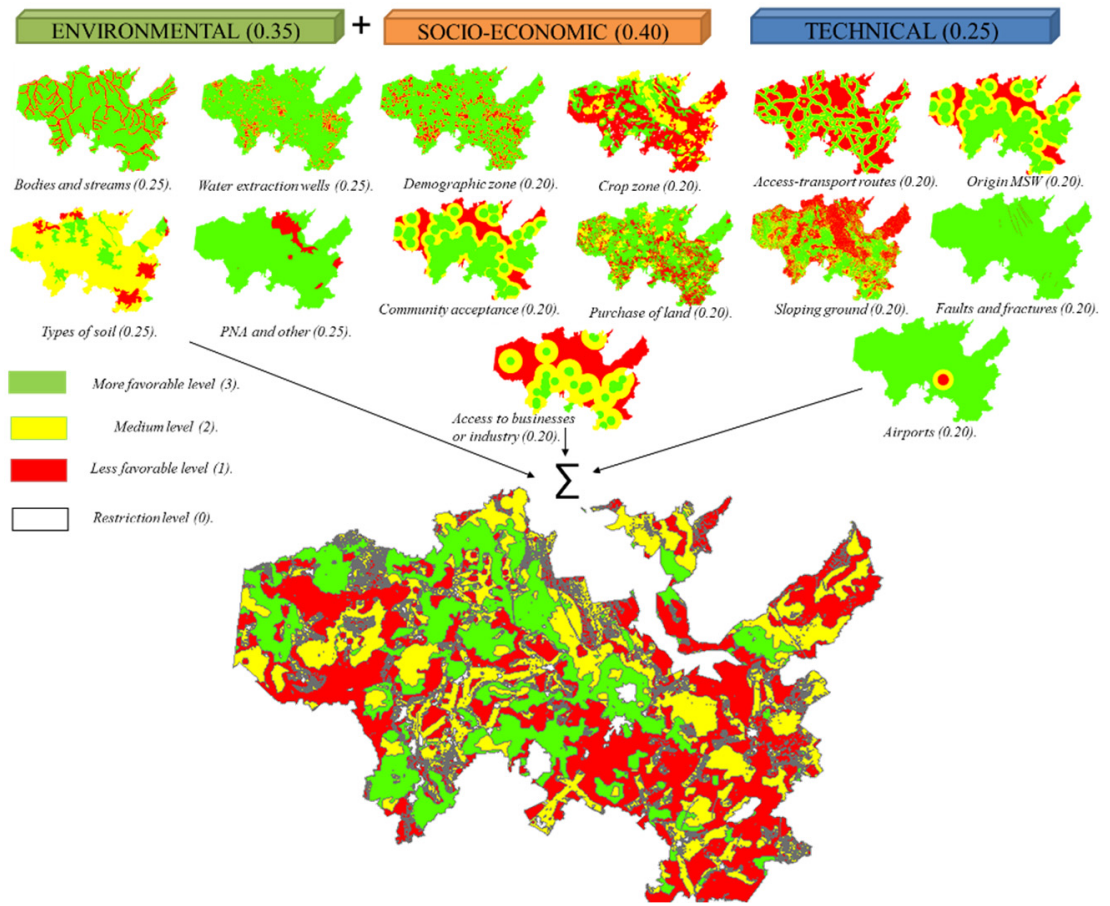

Figure 3: Thematic maps and MCE final development. 


\subsection{Selection of the optimal site for the installation of the IFMSW processing center through an origin-destination analysis}

MSW transportation is one of the most important aspects that has to be taken into account to analyze the economic feasibility and management optimization (collection, transfer, treatment and final disposal) of any study zone considered for locating MSW management infrastructure. Thus, it is necessary to carry out an origin-destination analysis to determine the optimal transportation route.

The objective of transportation planning is the optimal use of the road infrastructure and transportation means, and population mobility has to be factored in. It is important to consider the changes that may occur because of modifications in transportation systems. The socioeconomic characteristics of a region are valuable information to establish scenarios regarding the transportation system. These aspects are interrelated and thus changes in the characteristics of one of them automatically generate changes in the other.

\subsubsection{Determination of the optimal location sites}

In order to develop an origin-destination analysis, the georeferencing of the cement plants and the main MSW disposal sites (municipal and state landfills) currently operating in Hidalgo was performed by a GPS. Then, 21 preliminary optimal location points were found based on areas with a highly favorable suitability determined by the MCE and using the SIG software, ArcGis 10.2.2. Out of these 21 points, five were discarded because the long distance from the road network implied a greater investment cost to access the IFMSW processing center.

Once the 16 optimal points, the MSW handling sites and the cement plants were located, the analysis was divided in two phases. The first phase consisted of measuring each one of the distances in order to determine the shortest route from the MSW handling sites (origin) to the optimal location points (destination). The second phase was performed from the optimal location points (origin) to the cement plants (destination). Finally, the distances were multiplied by the waste transportation cost (freight), for both bulk waste transportation and processed waste transportation (IFMSW bales). The main difference with regard to waste transportation is the fact that compacted waste (IFMSW bales) permits to transport more material than bulk waste, and thus it is expected that the cost per kilogram of compacted waste will be lower.

Figure 4 shows the location of one of the three optimal points for the installation of the IFMSW processing center that were determined through the origindestination analysis. The first point is located outside Pachuca, in the eastern region, the second one is located in the western region, also outside Pachuca and the third point is located about $14 \mathrm{~km}$ north of Huichapan, in the western area of the state of Hidalgo. 


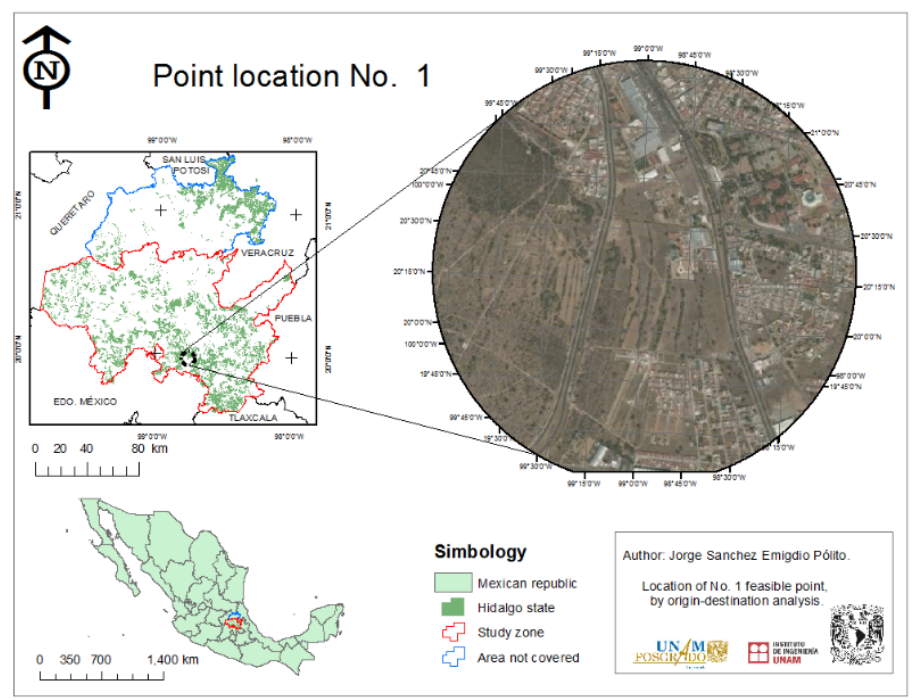

Figure 4: Location of the number one optimal point.

\section{References}

[1] INECC (2012). Nacional Institute of Ecology and Climate Change. Basic Diagnosis for Waste Integral Management. http:/www.inecc.gob.mx/ descargas/dgcenica/diagnostico_basico_extenso_2012.pdf

[2] Sánchez O. (2007). Integral management of municipal solid wastes in the municipalities of Actopan, San Salvador and el Arenal in the state of Hidalgo. Autonomous University of the State of Hidalgo, chemical research center, pp. 25-33.

[3] NOM-083-SEMARNAT (2003). Environmental protection specifications for site selection, design, construction, operation, monitoring, closure and complementary works of a MSW and SMW final disposal site. http://www.profepa.gob.mx/innovaportal/file/1306/1/nom-083-semarnat2003.pdf

[4] Sánchez, J., Estrada, R., Ramos, C., Carmona, R., Cano, P \& Semadeni, I. (1996). Solid waste transfer stations in urban areas (online)]. Joint publication of the National Institute of Ecology (INE) and the Mexican Association of the control of solid and hazardous wastes A.C., Series: Work Notebook 5. http://www2.inecc.gob.mx/publicaciones/download/105.pdf

[5] SEMARNAT (2010). Secretariat of Environment and Natural Resources. Criteria for the location, operation and closure of environmental infrastructure for collecting, transferring, separating and treating Municipal Solid Wastes and Wastes requiring Special Handling]. December 2010. Contract DGRMIS-DAC-DGFAUT-NO. 012/2010.

[6] NTEA-010-SMA-RS (2008). Environmental State Technical Standard. Requirements and specifications for the installation, operation and 
maintenance of infrastructure for collecting, transferring, separating and treating Municipal Solid Wastes and Wastes requiring Special Handling, for the State of Mexico.

[7] NADF-024-AMBT (2013). Environmental Standard for the Federal District. http://www.anipac.com/NADF024OFICIAL.pdf

[8] INEGI BII (2015). INEGI Information database. Available at http://www3.inegi.org.mx/sistemas/biinegi/

[9] PEPGIR of Hidalgo, 2011. State Program for the Prevention and Integral Management of Municipal Solid Wastes and Wastes requiring Special Handling in the State of Hidalgo, pp. 14-30.

[10] Cedano L. (2012). Energetic valorization of wastes as alternative fuels in cement plants. Polytechnic University of Valencia. Spain, Valencia, pp. 7181.

[11] Rojas-Valencia \& Marín M. (2014). Management and co-processing of Municipal Solid Wastes, Magazine IC Civil Engineering and Environmental Sciences, No. 545, pp. 20-23.

[12] Choy, H., Ko, K., Cheung, H., Fung C., Hui, W., Porter F. \& Mckay, G. (2004). Municipal solid waste utilization for integrated cement processing with waste minimization, A Pilot Scale Proposal. Process Safety and Environmental Protection, 82(B3) pp. 200-207.

[13] Queiroz L., Fortes P. \& Rubens C. (2013). Waste materials coprocessing in cement industry: Ecological efficiency of waste reuse. Renewable and Sustainable Energy Reviews, No. 19, pp. 200-207.

[14] Olivas U., Valdez J., Aldrete A., González M. \& Vera G. (2007). Areas suitable for setting up Maguey Cenizo plantations: Definition through Multi-Criteria Analysis and SIG, Mexican planta magazine, 30(4) 411-419.

[15] Araiza J. (2014). Location of Transfer Stations for Municipal Solid Wastes using SIG tools: a Study Case, Revista AIDIS de Engineering and Environmental Science: Research, development and practice, 7 (2), 78-86.

[16] Roé S., Rojas-Valencia \& Torres R. (2014). "Location of a site appropriate for building a waste management center urban solid by three methods", Journal AIDIS of Engineering and Environmental Sciences: Research, development and practice, Vol. 7, No. 2, pp. 141-153.

[17] Herrera B. (2014) Identification of potential areas for the handling of dangerous wastes in the department of Cundinamarca. Universidad Nacional de Colombia, Bogotá D.C, Colombia, pp. 13-16.

[18] De Pietri D., Dietrich, P., Mayo P. \& Carcagno A. (2011) Multi-Criteria Evaluation of the exposition to environmental risk through a geographic information system in Argentina. Revista Panam Public Health. Vol. 30, No. 4, pp. 377-387.

[19] Saaty T.L. (1980). The Analytic Hierarchy Process, McGraw-Hill, N.Y.

[20] Gómez M. \& Barredo J. (2005). Geographic Information Systems and Multi-Criteria Evaluation in Planning, 2nd edition; Updated, Editorial RAMA, Madrid, $276 \mathrm{pp}$.

[21] CONANP (2014). Protected Natural Areas. http://sig.conanp.gob.mx/ website/anpsig/viewer.htm 